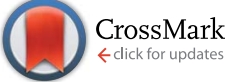

Cite this: Chem. Sci., 2015, 6, 2444

Received 30th December 2014 Accepted 2nd February 2015

DOI: $10.1039 / \mathrm{c} 4 \mathrm{sc} 04042 \mathrm{~b}$

www.rsc.org/chemicalscience

\title{
Self-assembled trinuclear arsenic and antimony macrobicycles $\uparrow$
}

\author{
Mary S. Collins, ${ }^{a}$ Robert Y. Choi, ${ }^{a}$ Lev N. Zakharov, ${ }^{b}$ Lori A. Watson, ${ }^{c}$ Benjamin P. Hay ${ }^{d}$ \\ and Darren W. Johnson*a
}

The synthesis of six trinuclear $\mathrm{Pn}_{3} \mathrm{~L}_{2}$ macrobicycles $(\mathrm{Pn}=\mathrm{As}, \mathrm{Sb})$ was achieved by self-assembly of a pnictogen trichloride and a 2,4,6-trisubstituted-1,3,5-benzenetrimethanethiol ligand. ${ }^{1} \mathrm{H}-\mathrm{NMR}$ spectroscopy reveals self-assembly in 1,1,2,2-tetrachloroethane is dynamic in solution producing two structural isomers. The symmetric and the asymmetric isomers (in which a single chloride ligand is cast in an opposing direction from other chlorides) of the $\mathrm{As}_{3} \mathrm{~L}_{2}$ complexes exist in a ca. $2: 1$ distribution, whereas only the symmetric isomer is observed in solution for $\mathrm{Sb}_{3} \mathrm{~L}_{2}$. Solvent effects appear to influence conformational isomerism and conversion to the final products. Macrobicycles were confirmed by ${ }^{1} \mathrm{H}$-NMR spectroscopy and X-ray crystallography and further studied by MP2/LANL2DZ optimizations.

\section{Introduction}

Supramolecular systems rely on multiple weak interactions to achieve stable, specific coordination to their hosts. Through creative ligand design, one can incorporate binding elements that enable directional self-assembly. Historically, a diversity of self-assembled systems incorporate the predictable coordination geometry of transition metals as a directional tool. ${ }^{1-6}$ Only recently has more effort been made toward understanding the supramolecular self-assembly of main group elements, including Group $15 .^{7-10}$ We utilize mercaptomethyl substituents as a preorganizing binding motif to accommodate the pnictogen's trigonal pyramidal geometry and thiophilicity. In addition to this predictable geometric configuration, electron density from the ligand provides a supporting non-covalent stabilizing force with the Lewis acidic pnictogen, known as a Pn $\cdots \pi$ interaction. ${ }^{11,12}$ Further studies by our laboratory have investigated how self-assembly is dictated by the structure of the dithiolate ligand by altering its length, width or the placement of steric bulk (Chart 1). ${ }^{13-16}$

${ }^{a}$ Department of Chemistry \& Biochemistry and Materials Science Institute, University of Oregon, Eugene, Oregon, USA 97403-1253. E-mail: dwj@uoregon.edu; Fax: +1541-346-4643; Tel: +1-541-346-1695

${ }^{b}$ CAMCOR - Center for Advanced Materials Characterization in Oregon, University of Oregon, Eugene, OR 97403-1443, USA

'Department of Chemistry, Earlham College, Richmond, IN 47374-4095, USA

${ }^{d}$ Supramolecular Design Institute, Oak Ridge, TN 37830-7185, USA

$\dagger$ Electronic supplementary information (ESI) available: Experimental procedures; NMR spectra; crystallographic information; and computational details, absolute energies and atomic coordinates of the discussed macrobicycles. CCDC 1041514-1041519. For ESI and crystallographic data in CIF or other electronic format see DOI: $10.1039 / \mathrm{c} 4 \mathrm{sc} 04042 \mathrm{~b}$
The 1,3,5-trisubstituted-2,4,6-triethyl benzene scaffold has been exploited in numerous supramolecular hosts since Mislow first demonstrated steric gearing of adjacent substituents, where each substituent is positioned in an alternating up-down arrangement. ${ }^{\mathbf{1 7}}$ While this preorganization technique has now been readily utilized to form supramolecular structures, ${ }^{18}$ its use with Group 15 metalloids (As, Sb) has not yet been explored, and led to some surprising structures. In this study, a series of six trinuclear arsenic and antimony supramolecular macrobicycles $\left[\mathrm{Pn}_{3} \mathbf{L}_{2} \mathrm{Cl}_{3}\right]$ were synthesized using a trisubstituted, trithiol ligand (Fig. 1). In addition to the syntheses, we address some unusual dynamic solution behaviour that arises from these new ligands that feature this steric gearing component. Typically, steric gearing serves as an effective preorganizational tool for metal-ligand-based supramolecular systems, providing enhanced thermodynamic stability of a complex and/or faster kinetics of formation. In this system we observed a surprising deviation where this gearing effect does not influence the rate of<smiles>Cc1cc(CS)c(C)cc1CS</smiles><smiles>SCc1ccc(CS)c2ccccc12</smiles><smiles>SCc1ccc2cc(CS)ccc2c1</smiles><smiles>Cc1c(CS)ccc(CS)c1C</smiles><smiles>SCc1cccc2c(CS)cccc12</smiles><smiles>SCc1ccc(Cc2ccc(CS)cc2)cc1</smiles>

Chart 1 Selection of dithiol ligands used for $\mathrm{Pn}$-thiolate selfassembly. 
A
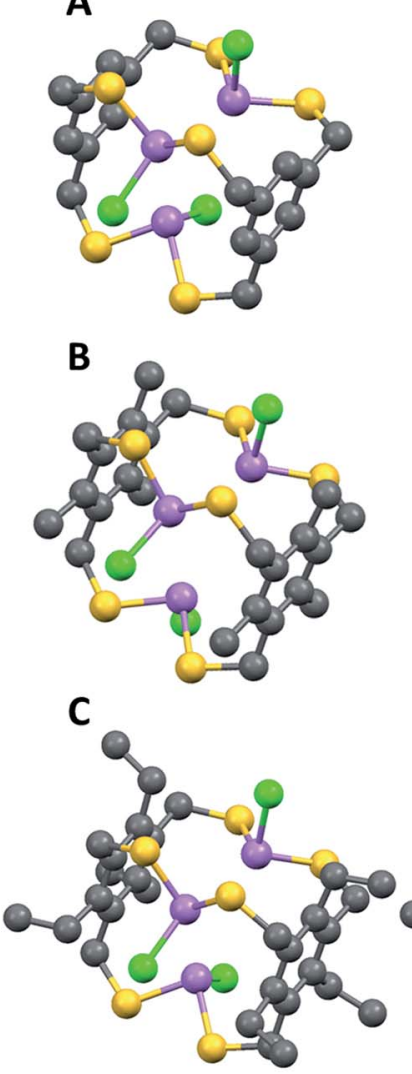

$\mathbf{F}$

E
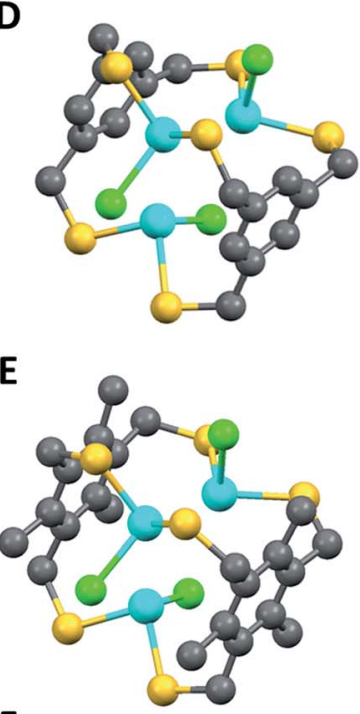

Q

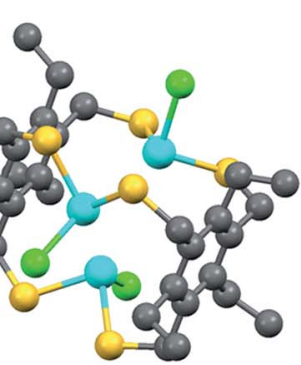

Fig. 1 Ball and stick representations (hydrogen atoms and solvent molecules are omitted for clarity) of the symmetric conformations of all new macrobicyclic structures reported: (a) $\left[\mathrm{As}_{3} \mathrm{~L}_{2}{ }_{2} \mathrm{Cl}_{3}\right]$ (b) $\left[\begin{array}{llllll}\left.\mathrm{As}_{3} \mathrm{~L}^{\mathrm{Me}}{ }_{2} \mathrm{Cl}_{3}\right] & \text { (c) }\left[\mathrm{As}_{3} \mathrm{~L}_{2}{ }_{2} \mathrm{Cl}_{3}\right] & \text { (d) }\left[\mathrm{Sb}_{3} \mathrm{~L}_{2} \mathrm{H}_{2} \mathrm{Cl}_{3}\right] & \text { (e) } & {\left[\mathrm{Sb}_{3} \mathrm{~L}^{\mathrm{Me}_{2}} \mathrm{Cl}_{3}\right]} & \text { (f) }\end{array}\right.$ $\left[\mathrm{Sb}_{3} \mathrm{Lt}_{2} \mathrm{Cl}_{3}\right.$ ].

self-assembly in mediating thiol reactivity with a pnictogen. Rather, interaction with the solvent and/or other external additives (such as chloride and tetrafluoroborate salts) more directly influences the course of the self-assembly reaction. For instance, a subtle change in solvent or the addition of a salt accelerate formation of macrobicycles in solution and additionally facilitates or prohibits a change in conformation to favour an unexpected, slightly higher energy asymmetric macrobicycle in tandem with the more stable, symmetric macrobicycle. Furthermore, close Pn $\cdots \pi_{\text {aryl }}$ contacts suggest a Pn $\cdots \pi_{\text {aryl }}$ interaction acts as a stabilizing force during assembly formation. These structures represent the first known trinuclear supramolecular arsenic- or antimony-thiolate assemblies. ${ }^{8}$

\section{Results and discussion}

\section{Symmetric and asymmetric $\mathrm{Pn}_{3} \mathrm{~L}_{2} \mathrm{Cl}_{3}$ macrobicycles}

To study the steric effect imparted by a trisubstituted benzene in arsenic-thiolate self-assembly, three bridging tridentate 2,4,6-trisubstituted-1,3,5-tris(mercaptomethyl)benzene ligand derivatives $\mathrm{H}_{3} \mathbf{L}^{\mathbf{R}}(\mathrm{R}=\mathrm{H}, \mathrm{Me}, \mathrm{Et})$ were synthesized (see ESI $\dagger$ for complete experimental details). When treated with a stoichiometric amount of $\mathrm{AsCl}_{3}$ in 1,1,2,2-tetrachloroethane (TCE), a
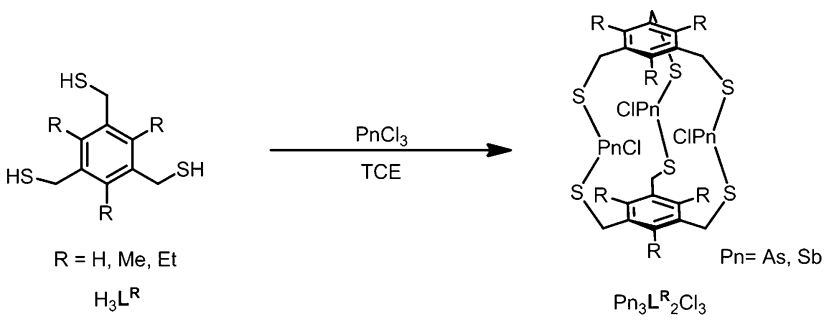

Scheme 1 Self-assembly of $\mathrm{Pn}_{3} \mathrm{~L}_{2} \mathrm{Cl}_{3}$ macrobicycles.

discrete trinuclear $\mathrm{As}_{3} \mathbf{L}_{2} \mathrm{Cl}_{3}$ macrobicycle emerges (Scheme 1). The unsubstituted metallacyclophane $\mathrm{As}_{3} \mathbf{L}_{2}{ }_{2} \mathrm{Cl}_{3}$ can alternatively be synthesized in a more facile method through the addition of tetrabutylammonium chloride at $0{ }^{\circ} \mathrm{C}$ in chloroform. The presence of a chloride guest was initially used to catalyze or template formation of a tetrahedral cage; however, $\mathrm{TBA}^{+} \mathrm{Cl}^{-}$instead induced a rapid precipitation of pure macrobicycles in the form of colorless needles ( $45 \%$ isolated crystalline yield after filtration, see ESI $\uparrow$ ).

Each prepared ligand derivative $\left(\mathrm{H}_{3} \mathbf{L}^{\mathbf{H}, \mathbf{M e}, \mathbf{E t}}\right)$ provides quantitative conversion to $\mathrm{As}_{3} \mathbf{L}_{2} \mathrm{Cl}_{3}$ upon treatment with $\mathrm{AsCl}_{3}$ as observed by ${ }^{1} \mathrm{H}$-NMR spectroscopy. Layering benzene over a solution of $\mathrm{H}_{3} \mathbf{L}^{\mathbf{M e}, \mathbf{E t}}$ and $\mathrm{AsCl}_{3}$ in TCE gave crystals suitable for

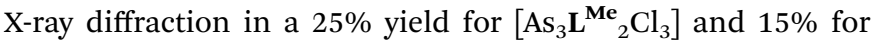
$\left[\mathrm{As}_{3} \mathbf{L}^{\mathrm{Et}}{ }_{2} \mathrm{Cl}_{3}\right]$, respectively, within one week. Antimony macrobicycles were isolated from a mixture of the corresponding $\mathrm{H}_{3} \mathbf{L}$ species and an excess of $\mathrm{SbCl}_{3}$ and crystallized by slow evaporation of TCE. The formation of $\mathrm{Sb}_{3} \mathbf{L}^{\mathbf{M e}, \mathbf{E t}}{ }_{2} \mathrm{Cl}_{3}$ complexes under these conditions could not be observed by ${ }^{1} \mathrm{H}-\mathrm{NMR}$ spectroscopy, ${ }^{20}$ and only partial conversion to $\left[\mathrm{Sb}_{3} \mathbf{L}^{\mathbf{H}}{ }_{2} \mathrm{Cl}_{3}\right]$ from $\mathrm{SbCl}_{3}$ and $\mathrm{H}_{3} \mathbf{L}^{\mathbf{H}}$ was observed when heating the solution to $70{ }^{\circ} \mathrm{C}$ (Fig. S18 $\dagger$ ). Nevertheless, crystallization of these solutions appears to induce formation of these macrocbicycles, and the structures of each $\left[\mathrm{Sb}_{3} \mathbf{L}_{2} \mathrm{Cl}_{3}\right]$ complex were determined by single crystal X-ray diffraction (ESI Table $1 \dagger$ ). These Sb-macrobicycles are then stable and can be redissolved TCE- $\mathrm{d}_{2}$ to verify their structure in solution (see Fig. S18, S21 and S24†).

By incorporating the 2,4,6-triethyl-substituted benzene scaffold, we envisioned the rate of self-assembly for both arsenic and antimony complexes to be favored over ligands that do not have such steric gearing components. While this preorganizing element has been successfully utilized to overcome high energy binding conformations or potential unfavorable binding entropies in relation to free host, guest or solvated host-guest complexes, ${ }^{21}$ we did not observe steric gearing as the primary driving force by ${ }^{1} \mathrm{H}-\mathrm{NMR}$ in the formation of pnictogen-thiolate macrobicycles as expected. The unsubstituted analogue $\left[\mathrm{As}_{3} \mathbf{L}_{2}{ }_{2} \mathrm{Cl}_{3}\right]$, bearing no steric gearing component, forms faster in solution ( 1 day) by ${ }^{1} \mathrm{H}-\mathrm{NMR}$ than its ethylsubstituted counterpart (4 days) in TCE-d ${ }_{2}$ (Fig. S6 and S16†).

However, evidence for steric gearing was observed in the crystalline state (single crystal structure data and parameters are shown in ESI Table 1, see ESI $\uparrow$ for complete details). As anticipated, none of the 2,4,6-triethyl substituents are directed toward the arsenic atoms in the crystal structure of $\left[\mathrm{As}_{3} \mathbf{L}^{\mathrm{Et}}{ }_{2} \mathrm{Cl}_{3}\right]$, since the 1,3,5-trimercaptomethyl groups of the ligand are all 
A

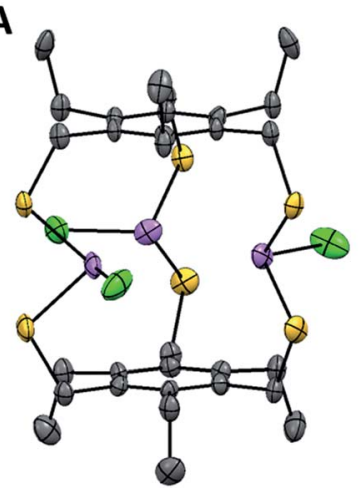

B

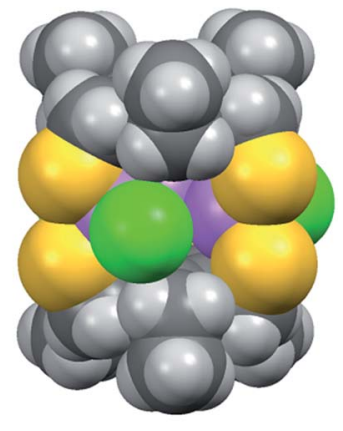

Fig. 2 ORTEP representation (50\% probability ellipsoids, hydrogen atoms and solvent molecules omitted for clarity) (A) and space filling representation (B) of the symmetric conformer of the $\mathrm{As}_{3} \mathrm{LE}_{2} \mathrm{Cl}_{3}$ macrobicycle. Arsenic is shown in purple, chloride in green, sulfur in yellow, carbon in black and hydrogen in gray.

pointed in that direction in order to converge on the three arsenic ions (Fig. 1C and 2). The electron-rich chlorine atoms coordinated to arsenic would also sterically disfavour the presentations of ethyl groups toward the center of the assembly. Interestingly, the increased steric bulk of the ethyl groups appears to affect the flexibility of the molecule to adopt a position that maintains the shortest As $\cdots \pi_{\text {aryl }}$ contact. This trend is apparent in both the As and Sb complexes, in which the $\mathrm{Pn} \cdots \pi_{\text {aryl }}$ contact increases in distance from $\left[\mathrm{Pn}_{3} \mathbf{L}_{2}{ }_{2} \mathrm{Cl}_{3}\right]$ to $\left[\mathrm{Pn}_{3} \mathbf{L}^{\mathrm{Me}}{ }_{2} \mathrm{Cl}_{3}\right]$ to $\left[\mathrm{Pn}_{3} \mathbf{L}^{\mathrm{Et}}{ }_{2} \mathrm{Cl}_{3}\right]$ (Table 1). As shown in Fig. $2 \mathrm{~A}$, each pnictogen atom is positioned endo relative to the aromatic ligand backbone, allowing for the stereochemically active pnictogen lone pairs to be directed inside the cavity of the macrobicycle. This arrangement facilitates an attractive $\mathrm{Pn} \cdots \pi_{\text {aryl }}$ interaction, which we have observed in many other structures of this type and use as a key design feature. ${ }^{11,16}$ The smallest As $\cdots \pi_{\text {aryl }}$ contacts in the $\mathrm{As}_{3} \mathbf{L}_{2} \mathrm{Cl}_{3}$ macrobicycles range between 3.17 and $3.27 \AA$, which is shorter than the sum of the van der waals radii for $\mathrm{C}$ and As $(3.7 \AA),{ }^{10,11,22-24}$ suggesting a stabilizing As $\cdots \pi$ interaction (Table 1). The close As $\cdots \pi_{\text {aryl }}$ contacts for the unsubstituted macrobicycle and the faster self-assembly of these congeners suggest that providing for As $\cdots \pi$ interactions in the ligand design may play a more significant directing role in the self-assembly than steric gearing. Moreover, the less restricted rotation around the $\mathrm{C}-$ aryl bonds in the less sterically hindered ligand may accelerate self-assembly. ${ }^{21}$

A

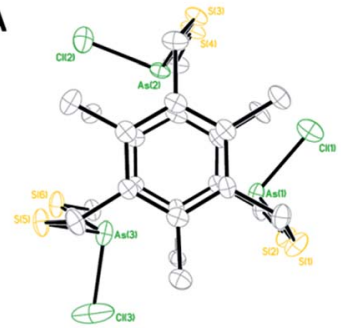

Symmetric

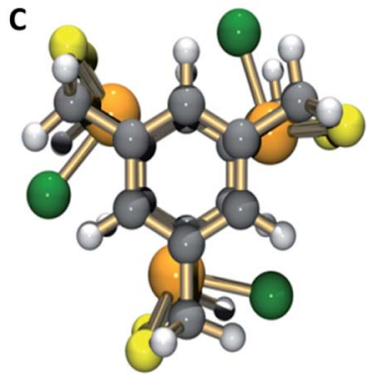

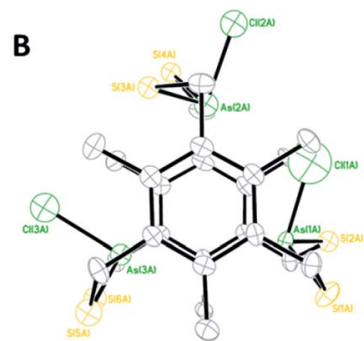

Asymmetric

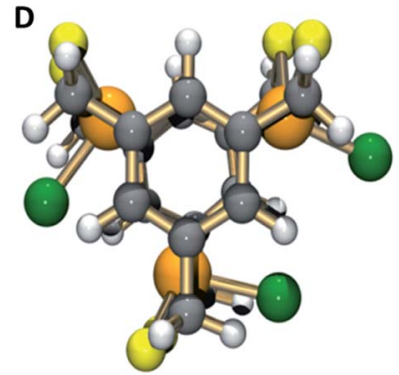

Fig. 3 (Top) ORTEP representations comparing the symmetric and asymmetric conformations of (a) sym- $\mathrm{As}_{3} \mathrm{~L} \mathrm{Me}_{2} \mathrm{Cl}_{3}$ and (b) asym- $\mathrm{As}_{3} \mathrm{~L}^{\mathrm{Me}}{ }_{2} \mathrm{Cl}_{3}$ macrobicycles. (Bottom) Ball and stick representations of optimized geometries (MP2/LANL2DZ) of (c) sym- $\mathrm{As}_{3} \mathrm{~L}_{2}{ }_{2} \mathrm{Cl}_{3}$, (d) asym- $\mathrm{As}_{3} \mathrm{~L}_{2}{ }_{2} \mathrm{Cl}_{3}$ macrobicycles.

${ }^{1} \mathrm{H}-\mathrm{NMR}$ characterization of As macrobicycles was performed in TCE- $d_{2}$. The methylene protons in the structure are inequivalent, creating an $\mathrm{AB}$ splitting system due to geminal coupling. Interestingly, all $\mathrm{As}_{3} \mathbf{L}_{2} \mathrm{Cl}_{3}$ derivatives exhibit the presence of an unusual, asymmetric isomer that accompanies the dominant symmetric isomer (sym- $\mathrm{As}_{3} \mathbf{L}^{\mathbf{M e}}{ }_{2} \mathrm{Cl}_{3}$ and asym- $\mathrm{As}_{3} \mathbf{L}^{\mathbf{M e}}{ }_{2} \mathrm{Cl}_{3}$, Fig. 3). The asymmetric conformer exhibits a framework in which a single chloride atom is pointing in the opposite direction relative to the other As- $\mathrm{Cl}$ bonds. This results in inequivalent methyl groups giving rise to singlets at $2.58,2.48$, and $2.43 \mathrm{ppm}$ in TCE$\mathrm{d}_{2}$. A similar type of symmetric $v s$. asymmetric isomerism was previously observed in two-fold symmetric, naphthalene-based arsenic-thiolate $\mathrm{As}_{2} \mathrm{~L}_{2} \mathrm{Cl}_{2}$ macrocycles, in which a single ligand "flips" causing the loss of $\mathrm{C}_{2}$ symmetry of the complex. ${ }^{25}$ Fig. 4 shows the mixture of sym- and asym- $\mathrm{As}_{3} \mathbf{L}^{\mathbf{M e}_{2}} \mathrm{Cl}_{3}$ macrobicycles obtained from dissolving single crystals of $\mathrm{As}_{3} \mathbf{L}^{\mathbf{M e}_{2}} \mathrm{Cl}_{3}$ and shows the $\mathrm{AB}$ splitting pattern observed for the methylene protons $\left(\mathrm{H}^{\mathrm{a}}\right.$ in figure). From integrating the resonances of each structure, it was determined that the symmetric isomer is favoured over the asymmetric isomer by a $63: 37$ ratio. The relative

Table 1 Select distances and bond angles for $\mathrm{As}_{3} \mathrm{~L}_{2} \mathrm{Cl}_{3}$ and $\mathrm{Sb}_{3} \mathrm{~L}_{2} \mathrm{Cl}_{3}$ macrobicycles ${ }^{a}$

\begin{tabular}{|c|c|c|c|c|c|}
\hline & $\mathrm{As}_{3} \mathbf{L}_{2}^{\mathbf{H}} \mathrm{Cl}_{3}$ & $\mathrm{As}_{3} \mathbf{L}^{\mathbf{M e}}{ }_{2} \mathrm{Cl}_{3}$ & $\mathrm{As}_{3} \mathbf{L}^{\mathbf{E t}}{ }_{2} \mathrm{Cl}_{3}$ & $\mathrm{Sb}_{3} \mathbf{L}^{\mathbf{M e}}{ }_{2} \mathrm{Cl}_{3}$ & $\mathrm{Sb}_{3} \mathbf{L}^{\mathrm{Et}}{ }_{2} \mathrm{Cl}_{3}$ \\
\hline $\operatorname{Pn}-\mathrm{S}(\AA)^{b}$ & $2.209(9)$ & $2.197(9)$ & $2.217(2)$ & $2.400(4)$ & $2.403(2)$ \\
\hline $\operatorname{Pn} \cdots \operatorname{Pn}(\AA)^{b}$ & $3.882(13)$ & $4.40(19)$ & $4.110(2)$ & $3.768(34)$ & $4.023(1)$ \\
\hline $\operatorname{Pn} \cdots \mathrm{C}_{\text {aryl }}(\AA)^{c}$ & $3.169(8)$ & $3.211(8)$ & $3.269(6)$ & $3.223(7)$ & $3.386(5)$ \\
\hline
\end{tabular}

${ }^{a} \mathrm{Sb}_{3} \mathbf{L}_{2}{ }_{2} \mathrm{Cl}_{3}$ not included due to significant disorder in structure. ${ }^{b}$ Denotes an averaged value. ${ }^{c}$ Value provided corresponds to shortest Pn $\cdots \mathrm{C}_{\text {aryl }}$ contact. 


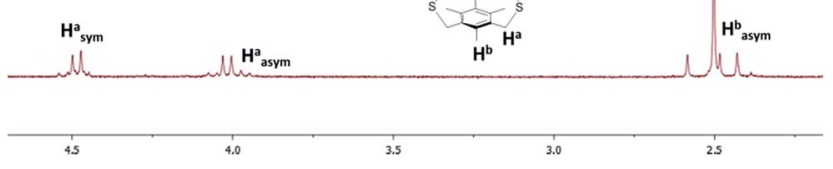

Fig. $4{ }^{1} \mathrm{H}$ NMR spectrum for $\mathrm{As}_{3} \mathrm{~L}^{\mathrm{Me}}{ }_{2} \mathrm{Cl}_{3}$ macrobicycle. The signals from the symmetric and asymmetric macrobicycle are labeled.

stability of the two different isomers was also investigated with electronic structure calculations. MP2/LANL2DZ geometry optimizations revealed the symmetric, unsubstituted As macrobicycle to be $3.63 \mathrm{kcal} \mathrm{mol}^{-1}$ lower in energy than the asymmetric isomer (Fig. 3C and D).

While a variation in the dithiolate ligand core appeared to dictate the isomer ratio in related studies on $\mathrm{As}_{2} \mathrm{~L}_{2} \mathrm{Cl}_{2}$ macrocycles ${ }^{26}$ in the case of the macrobicycles the substitution at the 2,4,6 position did not affect the sym : asym ratio between derivatives in solution as estimated by ${ }^{1} \mathrm{H}$ NMR spectroscopy: $68: 32$ $\left(\left[\mathrm{As}_{3} \mathbf{L}_{2}{ }_{2} \mathrm{Cl}_{3}\right]\right), 63: 37\left(\left[\mathrm{As}_{3} \mathbf{L}^{\mathbf{M e}}{ }_{2} \mathrm{Cl}_{3}\right]\right)$, and $69: 31\left(\left[\mathrm{As}_{3} \mathbf{L}^{\mathbf{E t}}{ }_{2} \mathrm{Cl}_{3}\right]\right)$. Given that the sym-isomers are favoured by this $\sim 2: 1$ ratio in solution, then at $25{ }^{\circ} \mathrm{C}$ these $s y m$-isomers are ca. $0.4 \mathrm{kcal} \mathrm{mol}^{-1}$ more stable than the asym-isomers. The difference between the relative energy of the two isomers in solution versus that calculated in vacuum presumably reflects the influence of solvation. Additionally, ${ }^{1} \mathrm{H}-\mathrm{NMR}$ reveals a slow equilibrium between sym- and asym- $\mathrm{As}_{3} \mathbf{L}_{2} \mathrm{Cl}_{3}$ : each isomer has a distinct NMR spectrum at room temperature, meaning the equilibration between the two species is slow on the NMR timescale. However, upon dissolving single crystals of $\mathrm{As}_{3} \mathbf{L}_{2} \mathrm{Cl}_{3}$ macrobicycles, the equilibrium mixture of sym- and asym-isomers is established within minutes, suggesting this equilibration is fast on the seconds to minutes timescale.

Structural characterization using single crystal X-ray diffraction is in agreement with solution state NMR studies, suggesting the symmetric conformers are again the dominant species.

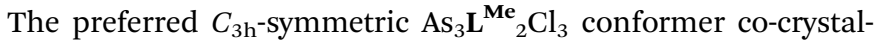
lizes with the $C_{\mathrm{s}}$ asymmetric complex in a $90: 10$ ratio (Fig. 3A and $\mathrm{B}$ ). The opposing chloride in the asymmetric structure shows a significant amount of disorder. The crystal packing structures for ethyl- and methyl-substituted macrobicycles reveal a formation of columns in a herringbone fashion (Fig. S12 and $\mathrm{S} 17 \dagger$ ). Discernible stabilizing forces in each As-containing macrobicycle are intermolecular interactions seen in the form of short $\mathrm{S} \cdots \mathrm{S}$ contacts between $3.28-3.67 \AA$ A. In addition, a single benzene molecule co-crystallizes orthogonal to the $1 \mathrm{D}$ stacks in the crystal structure of the unsubstituted derivative, $\left[\mathrm{As}_{3} \mathbf{L}_{2}{ }_{2} \mathrm{Cl}_{3}\right]$.

\section{Effect of external additives and solvent dependence}

Due to the low energy barrier of conversion from the symmetric macrobicycle to the asymmetric macrobicycle, the kinetic stability of the macrobicycles was tested by heating the solution to $120{ }^{\circ} \mathrm{C}$ over several days. Both -sym and -asym conformers were kinetically stable under these conditions and showed no apparent conversion from asym- $\mathrm{As}_{3} \mathrm{~L}_{2} \mathrm{Cl}_{3}$ to the symmetric complex on the NMR timescale. Interestingly, the self-assembled isomerism was found to be strongly influenced by solvent effects as revealed by solution studies performed in deuterated chloroform. Reacting unsubstituted ligand $\mathrm{H}_{3} \mathbf{L}^{\mathbf{H}}$ with $\mathrm{AsCl}_{3}$ results in only partial conversion to the macrobicycle after more than a week in $\mathrm{CDCl}_{3}$; whereas $100 \%$ conversion to the macrobicycle in TCE- $\mathrm{d}_{2}$ is achieved in only one day, suggesting some unusual solvent effect is at play in TCE that facilitates macrobicycle formation. In benzene, insoluble kinetic intermediates rapidly precipitate from the reaction solution, resulting in limited conversion to macrobicycle. The degree of solubility for these oligomeric intermediates also appears to impact the formation of a single stereoisomer over another. This was most apparent in tetrahydrofuran where only the symmetric isomer is formed in solution; whereas, dichloromethane, benzene, and chloroform hinder the self-assembly of both sym/asym-macrobicycles. Supplementary to solvent effects, tetrabutylammonium tetrafluoroborate increases the relative rate of selfassembly in TCE giving complete conversion to $\mathrm{As}_{3} \mathbf{L}_{2}{ }_{2} \mathrm{Cl}_{3}$ in 8 minutes without subsequent precipitation of product seen with $\mathrm{TBA}^{+}$chloride. ${ }^{19}$ This change in reactivity when subjected to an external agent is another unusual example of a selfassembly reaction driven by a small molecule that facilitates the organization process, ${ }^{27,28}$ and augurs well for the formation of even greater, more intricate self-assembled systems using related thiol ligands and main group ion building blocks.

$C_{3 \mathrm{~h}}$-Symmetric $\mathrm{Sb}_{3} \mathbf{L}_{2} \mathrm{Cl}_{3}$ macrobicycles appear to be more static in solution when compared to the arsenic-based congeners as only symmetric macrobicycles are present in TCE- $\mathrm{d}_{2}$ suggesting the asymmetric isomers are much more stable relatively. Similar to its As counterpart, the $\mathrm{Sb}_{3} \mathbf{L}_{2}{ }_{2} \mathrm{Cl}_{3}-s y m$ is only $4.46 \mathrm{kcal} \mathrm{mol}^{-1}$ lower in energy than the asymmetric conformer calculated via MP2/LANL2DZ. Single crystal X-ray diffraction of $\left[\mathrm{Sb}_{3} \mathbf{L}^{\mathbf{M e}, \mathbf{E t}}{ }_{2} \mathrm{Cl}_{3}\right]$ reveal columnar packing in a herringbone pattern with short $\mathrm{S} \cdots \mathrm{S}$ contacts of $3.62 \AA$ and intramolecular $\mathrm{Sb} \cdots \mathrm{C}_{\text {aryl }}$ distances ranging between 3.24-3.39 (VDW radii is $3.85 \AA$ for Sb). Similar to As macrobicycles, the sulfur-sulfur interaction poses as the prominent stabilizing factor in crystal packing. However, the solid state structure of $\mathrm{Sb}_{3} \mathbf{L}^{\mathbf{E t}}{ }_{2} \mathrm{Cl}_{3}$ adopts more sulfur contacts between the layers of columns than $\left[\mathrm{As}_{3} \mathbf{L}^{\mathbf{E t}}{ }_{2} \mathrm{Cl}_{3}\right.$ ] (Fig. S26†). A similar trend in $\mathrm{Pn} \cdots \pi$ interaction is observed, with the distance in this stabilizing force increasing with added steric bulk at the ligand core. Surprisingly, no evidence for asym- $\mathrm{Sb}_{3} \mathbf{L}_{2} \mathrm{Cl}_{3}$ conformers was observed in solution, although under certain conditions the asym-conformer does contribute to a minor disordered component in single crystal X-ray structures. These disordered crystals still lead to NMR spectra indicating only the presence of sym- $\mathrm{Sb}_{3} \mathbf{L}_{2} \mathrm{Cl}_{3}$ macrobicycles. This is in stark conflict with previous studies on dinuclear $\mathrm{Pn}_{2} \mathrm{~L}_{3}$ cryptands, which revealed added stability in $\mathrm{Sb}$ (and $\mathrm{Bi}$ ) complexes over the As derivatives. $^{25}$

\section{Conclusion}

In conclusion, this is the first report of a series of self-assembled trinuclear As(III) and $\mathrm{Sb}(\mathrm{III})$ coordination complexes, and we 
report the syntheses of six such macrobicyclic assemblies. The As-derivatives exist in two different conformations: a slightly more stable $C_{3 \mathrm{~h}}$-symmetric structure and an asymmetric conformer that lacks the three-fold symmetry. Steric gearing at the tripodal core of the 1,3,5-trisubstituted benzene ring does not appear to influence the rate of self-assembly in solution nor the equilibrium between different macrobicyclic conformers, negating the presence of any apparent steric gearing effects during self-assembly and dynamic motion in solution. However, X-ray crystallography suggests pnictogen $\cdots \pi_{\text {aryl }}$ interactions may act as a strong directing force in self-assembly complementary to steric gearing. Additionally, the selfassembly of these macrobicycles is sometimes enhanced and/or suppressed by different organic solvents as well as the addition of chloride and tetrafluoroborate salts.

\section{Acknowledgements}

The authors thank the University of Oregon for partial support of this work. D.W.J. is a Scialog Fellow of Research Corporation for Science Advancement (Award ID 20317). We thank Dr Charlie Peck and the Earlham College Cluster Computing Group for providing computational resources used in this work (http://cluster.earlham.edu).

\section{Notes and references}

1 A. Schmidt, A. Casini and F. E. Kühn, Coord. Chem. Rev., 2014, 275, 19-36.

2 R. A. Bilbeisi, J.-C. Olsen, L. J. Charbonnière and A. Trabolsi, Inorg. Chim. Acta, 2014, 417, 79-108.

3 M. M. J. Smulders, I. A. Riddell, C. Browne and J. R. Nitschke, Chem. Soc. Rev., 2013, 42, 1728-1754.

4 D. L. Caulder and K. N. Raymond, J. Chem. Soc., Dalton Trans., 1999, 1185-1200.

5 K. Harris, D. Fujita and M. Fujita, Chem. Commun., 2013, 49, 6703-6712.

6 N. J. Young and B. P. Hay, Chem. Commun., 2013, 49, 13541379.

7 M. M. Watt, M. S. Collins and D. W. Johnson, Acc. Chem. Res., 2013, 46, 955-966.

8 N. R. Lindquist, T. G. Carter, V. M. Cangelosi, L. N. Zakharov and D. W. Johnson, Chem. Commun., 2010, 46, 3505-3507.

9 M. E. Carnes, N. R. Lindquist and D. W. Johnson, Main Group Supramolecular Coordination Chemistry in
Encyclopedia of Supramolecular Chemistry, ed. J. L. Atwood, J. W. Steed and K. J. Wallace, Taylor and Francis, New York, 2012.

10 M. A. Pitt and D. W. Johnson, Chem. Soc. Rev., 2007, 36, 1441-1453.

11 H. Schmidbaur and A. Schier, Organometallics, 2008, 27, 2361-2395.

12 J. Zukerman-Schpector, A. Otero-de-la-Roza, V. Luaña and E. R. T. Tiekink, Chem. Commun., 2011, 47, 7608-7610.

13 V. M. Cangelosi, L. N. Zakharov, S. A. Fontenot, M. A. Pitt and D. W. Johnson, Dalton Trans., 2008, 3447-3453.

14 V. M. Cangelosi, L. N. Zakharov, J. L. Crossland, B. C. Franklin and D. W. Johnson, Cryst. Growth Des., 2010, 10, 1471-1473.

15 M. A. Pitt, L. N. Zakharov, K. Vanka, W. H. Thompson, B. B. Laird and D. W. Johnson, Chem. Commun., 2008, 3936-3938.

16 V. M. Cangelosi, M. A. Pitt, W. J. Vickaryous, C. A. Allen, L. N. Zakharov and D. W. Johnson, Cryst. Growth Des., 2010, 10, 3531-3536.

17 D. J. Iverson, G. Hunter, J. F. Blount, J. R. Damewood and K. Mislow, J. Am. Chem. Soc., 1981, 103, 6073-6083.

18 G. Hennrich and E. V. Anslyn, Chem.-Eur. J., 2002, 8, 2218.

19 M. E. Carnes, M. S. Collins, N. R. Lindquist, E. GuzmánPercástegui, M. D. Pluth and D. W. Johnson, Chem. Commun., 2014, 50, 73-75.

20 W. J. Vickaryous, L. N. Zakharov and D. W. Johnson, Main Group Chem., 2006, 5, 51-59.

21 X. Wang and F. Hof, Beilstein J. Org. Chem., 2012, 8, 1-10.

22 T. Probst, O. Steigelmann, J. Riede and H. Schmidbaur, Chem. Ber., 1991, 124, 1089-1093.

23 H. Schmidbaur, W. Bublak, B. Huber and G. Müller, Angew. Chem., Int. Ed. Engl., 1987, 26, 234-236.

24 H. Schmidbaur, R. Nowak, O. Steigelmann and G. Müller, Chem. Ber., 1990, 123, 1221-1226.

25 V. M. Cangelosi, T. G. Carter, J. L. Crossland, L. N. Zakharov and D. W. Johnson, Inorg. Chem., 2010, 49, 9985-9992.

26 V. M. Cangelosi, A. C. Sather, L. N. Zakharov, O. B. Berryman and D. W. Johnson, Inorg. Chem., 2007, 46, 9278-9284.

27 T. Hasell, X. Wu, J. T. A. Jones, J. Bacsa, A. Steiner, T. Mitra, A. Trewin, D. J. Adams and A. I. Cooper, Nat. Chem., 2010, 2, 750-755.

28 S. Otto, R. L. E. Furlan and J. K. M. Sanders, Science, 2002, 297, 590-593. 